\title{
RACK LENGTH IN BOTTOM INTAKE SYSTEMS
}

\author{
LUIS G. CASTILLO ${ }^{1}$, JUAN T. GARCÍA ${ }^{1}$, PATRICIA HARO ${ }^{2}$ \& JOSÉ M. CARRILLO ${ }^{1}$ \\ ${ }^{1}$ Departamento de Ingeniería Civil, Universidad Politécnica de Cartagena, Spain \\ ${ }^{2}$ Departamento de Ingeniería Civil y Ambiental, Escuela Politécnica Nacional, Ecuador
}

\begin{abstract}
Bottom intake systems, made by racks longitudinally disposed in the flow direction, are classically used to derive mean flows in continuous mountain rivers with intensive sediment transport. They are known as Caucasian or Tyrolean Intakes. Nowadays, works are also being addressed to study these intakes in order to derive flash floods from ephemeral rivers in semiarid zones to collect runoff and improve the availability of resources. In the design of bottom intake systems, the length of rack is an important variable. This article includes several formulations that come from experimental works in laboratory and in prototype. The objective is to complement and update those works, including some empirical expressions proposed and experimental works developed since 2010 at the Universidad Politécnica de Cartagena. Rack length values for different flow rates are presented in dimensionless form $\left(L / h_{c}-\right.$ required rack length over critical depth) for the spacing area ratio over total area (void fraction $m$ ) of values $0.12,0.28$ and 0.60 . These lengths present important differences depending on the conditions for which they were obtained, for example type of bars (circular or flat), spacing between the bars or the slope adopted by the rack. Values of the dimensionless rack length considering obstruction factors are also analysed. The Froude similitude criterion has been considered to obtain prototype values from the laboratory experimental conditions.

Keywords: bottom racks, design conditions, rack length, sediment transport, void ratio.
\end{abstract}

\section{INTRODUCTION}

Krochin [1] describes mountain streams as that which has strong longitudinal slopes, intense short-term precipitation, large flow variation and high sediment content with scarce fines (clean water in dry season).

On the other hand, semiarid zones are characterized by having low precipitation levels with huge temporal and spatial variability, low soil moisture, lack of vegetation cover, steep morphology and great sediment transport capacity by runoff [2].

Tyrolean or Caucasian Intakes have been used in mountain river basins due to their flow derivation capacity with moderate-high sediment transport, which facilitates their operation and maintenance when they are located in places of difficult access [1].

In semiarid basins, bottom rack intakes could be implemented in the upper zones in order to derivate flash floods with high sediment transport capacity during the wet season. Detailed studies of design parameters are required in order to optimize the structure sizing and guarantee design flow derivation [2-4].

\section{DESIGN CONSIDERATIONS}

Bottom intake systems are usually composed of a rack with parallel bars arranged longitudinally to the streamflow and located with a certain inclination $(\tan \theta)$ over an intake gallery (built into a weir), or in the bottom channel, that facilitates flow derivation.

Principal factors of intakes design are: the ratio of clear opening area and total area of the rack (void ratio, $m$ ), the bars geometry, the rack slope - that reduces rack occlusion and facilitates self-cleaning, the approximation conditions and flexion resistance capacity of steel profiles (considering blows or abrasion caused by materials transported by avenues) among others. 


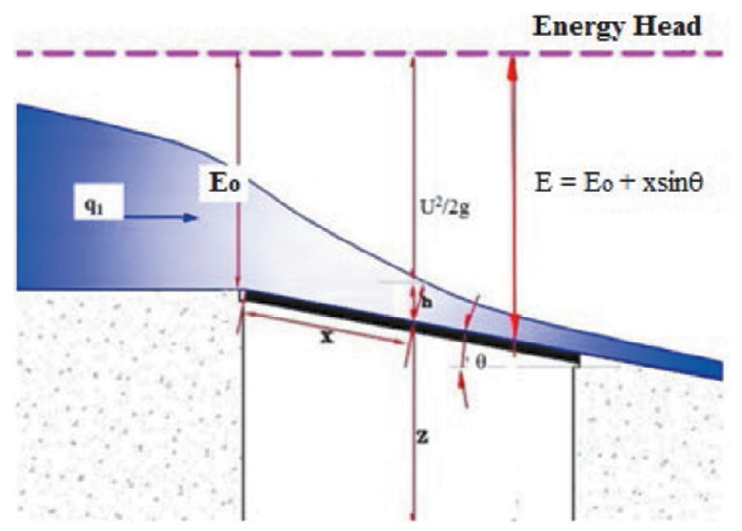

(a)

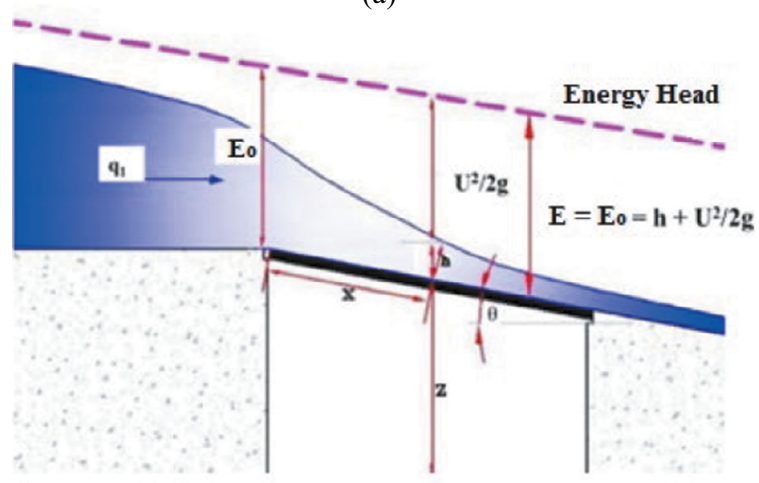

(b)

Figure 1: Bottom rack scheme considering: (a) horizontal energy level; (b) constant specific energy - energy level parallel to the bottom rack (García [2]).

Bottom racks behaviour have been analysed by different authors like it is mentioned in García [2]. Intake racks systems present three-dimensional and spatially varied flow with high turbulence level. Some hypotheses are adopted in order to simplify setting parameters:

- Hydrostatic pressure distribution along the rack.

- One-dimensional flow with decreasing flow.

- Energy conservation equation.

- Discharge coefficient experimentally set.

Regarding the loss of energy, some studies assume that it is negligible (horizontal energy level) as shown in Fig. 1a, while in other cases, it is based on the constant specific energy hypothesis along the rack (Fig. 1b), assuming critical depth at the beginning of the rack.

\section{BOTTOM RACK LENGTH}

This work exposes several formulations from different researches in order to calculate the wetted rack length necessary to derive the design flow in bottom intake systems. These formulae come from experimental work in laboratory and in prototype that are collected in the bibliography. The results obtained from its application are shown in Figs 2-4 for the cases of 
void ratio $m=0.60\left(b_{1}=0.15 \mathrm{~m}\right.$ and $\left.b_{w}=0.10 \mathrm{~m}\right), m=0.28\left(b_{1}=0.039 \mathrm{~m}\right.$ and $\left.b_{w}=0.10 \mathrm{~m}\right)$ and $m=0.12\left(b_{1}=0.014 \mathrm{~m}\right.$ and $\left.b_{w}=0.10 \mathrm{~m}\right)$, respectively, being $b_{1}$ the spacing between bars and $b_{w}$ the bar wide. Flat T-shaped, flat prismatic, circular and prismatic rounded bars are considered; and $20 \%$ of slope. In the case of 0.60 void ratio, values can be compared with those measured in prototype [5] for circular bars and $20 \%$ of slope.

Figures 2-4 distinguish different kinds of rack lengths: $L$ is the total rack length for deriving a design flow; $L_{1}$ the maximum length reached by water in the slit between two bars; and $L_{2}$ the envelope of lengths measured in prototype for different flow values (envelope of $L$ ) proposed by Drobir [5]. Different types of bars used in each formulation setting are shown in these figures, while the laboratory setup and detail of equations are collected in the Appendix.

In case of $m=0.60$ (Fig. 2) and circular bars, dimensionless rack length as a function of critical flow $\left(L / h_{c}\right)$ oscillates from 1.70 to 2.60. Envelope of Drobir is located over this group of curves with the value of 3.70 , for specific flow of $q=1.00 \mathrm{~m}^{3} / \mathrm{s} / \mathrm{m}$. In the case of T-shaped bars, $L / h$ varies from 2.70 to 4.10 when sediment occlusion is not considered. At the top of the Fig. 2 are the values of $L / h_{c}$ equal to 4.40 and 5.40, which correspond to $15 \%$ and $30 \%$ of occlusion factor proposed in the equation of Krochin [1], respectively.

For $m=0.28$ and circular bars, considering the specific flow of $1.00 \mathrm{~m}^{3} / \mathrm{s} / \mathrm{m}$, dimensionless rack length as a function of critical flow $\left(L / h_{c}\right)$ oscillates from 2.90 to 4.30 . In the case of T-shaped bars, $L / h_{c}$ varies from 5.30 to 8.10 when sediment occlusion is not considered. At the top of the Fig. 3 are the values of 9.50 and 11.30 , which correspond to $L / h$ with $15 \%$ and $30 \%$ of occlusion factor, respectively. Krochin [1] proposes $f$ values of up to $30 \%$ for channels with high sediment transport and this has been experimentally proven in Castillo et al. [3].

Finally, for $m=0.12$ and circular bars, dimensionless rack length as a function of critical flow $\left(L / h_{c}\right)$ oscillates from 4.40 to 8.80 , for specific flow of $q=1.00 \mathrm{~m}^{3} / \mathrm{s} / \mathrm{m}$. For T-shaped
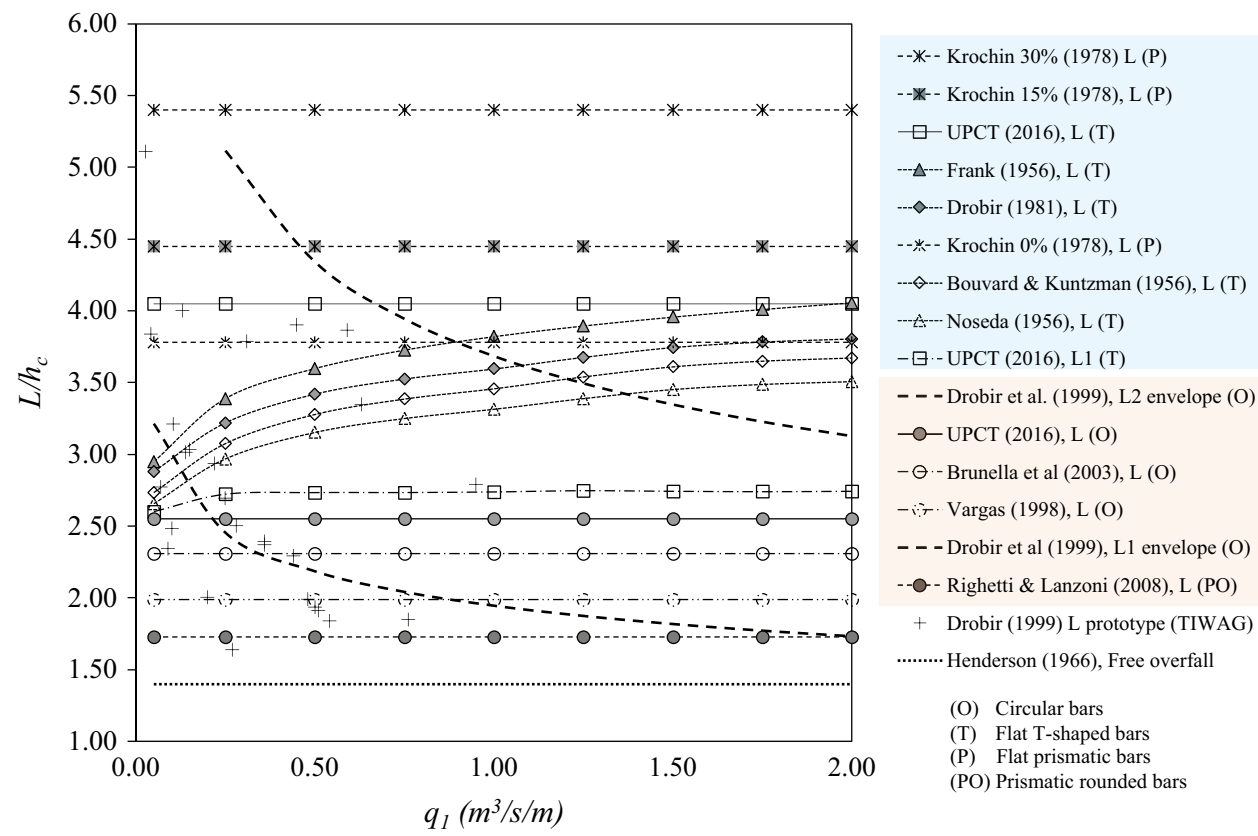

Figure 2: Dimensionless wetted rack length as a function of critical flow depth, $h_{c}$, approximation proposed in literature for racks with void ratio $m=0.60$. 


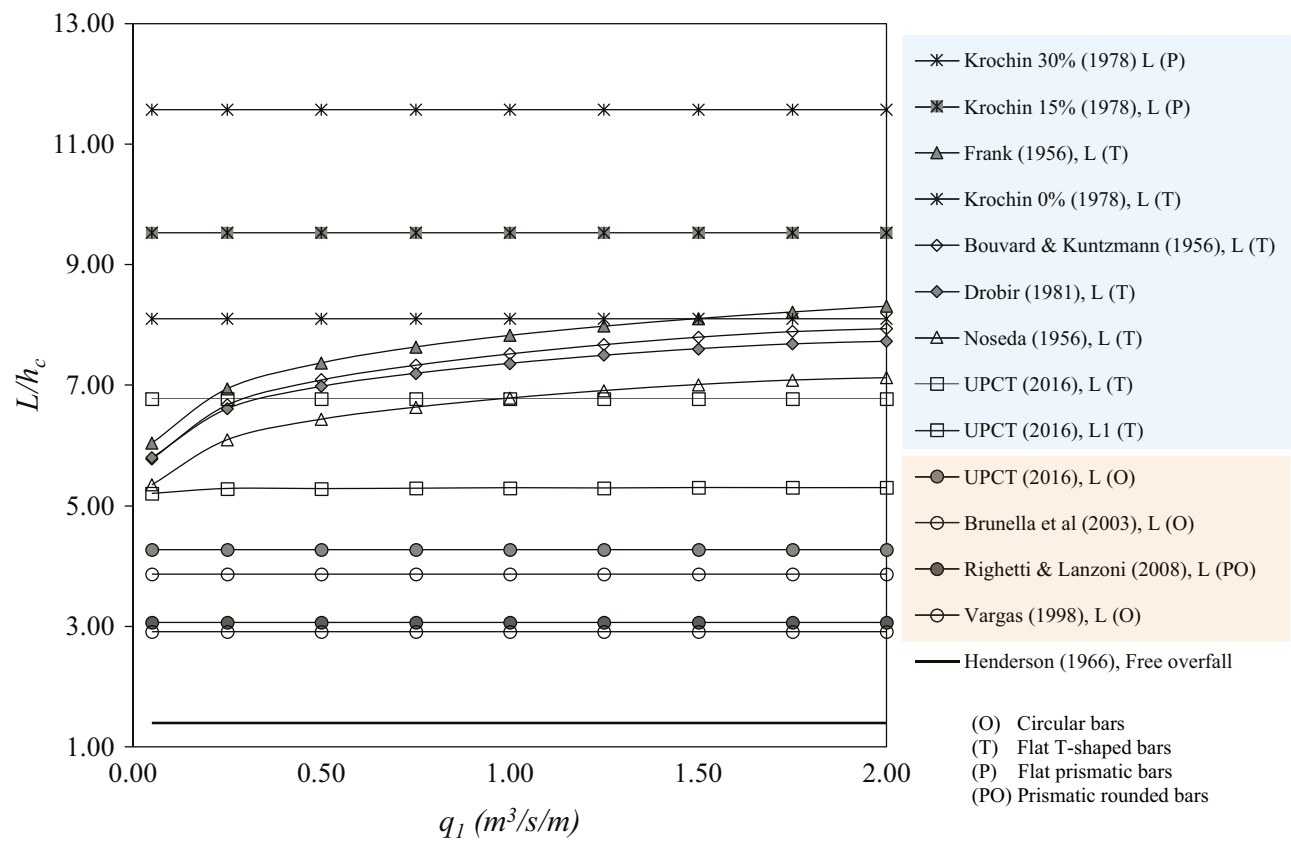

Figure 3: Dimensionless wetted rack length as a function of critical flow depth, $h_{c}$, approximation proposed in literature for racks with void ratio $m=0.28$.

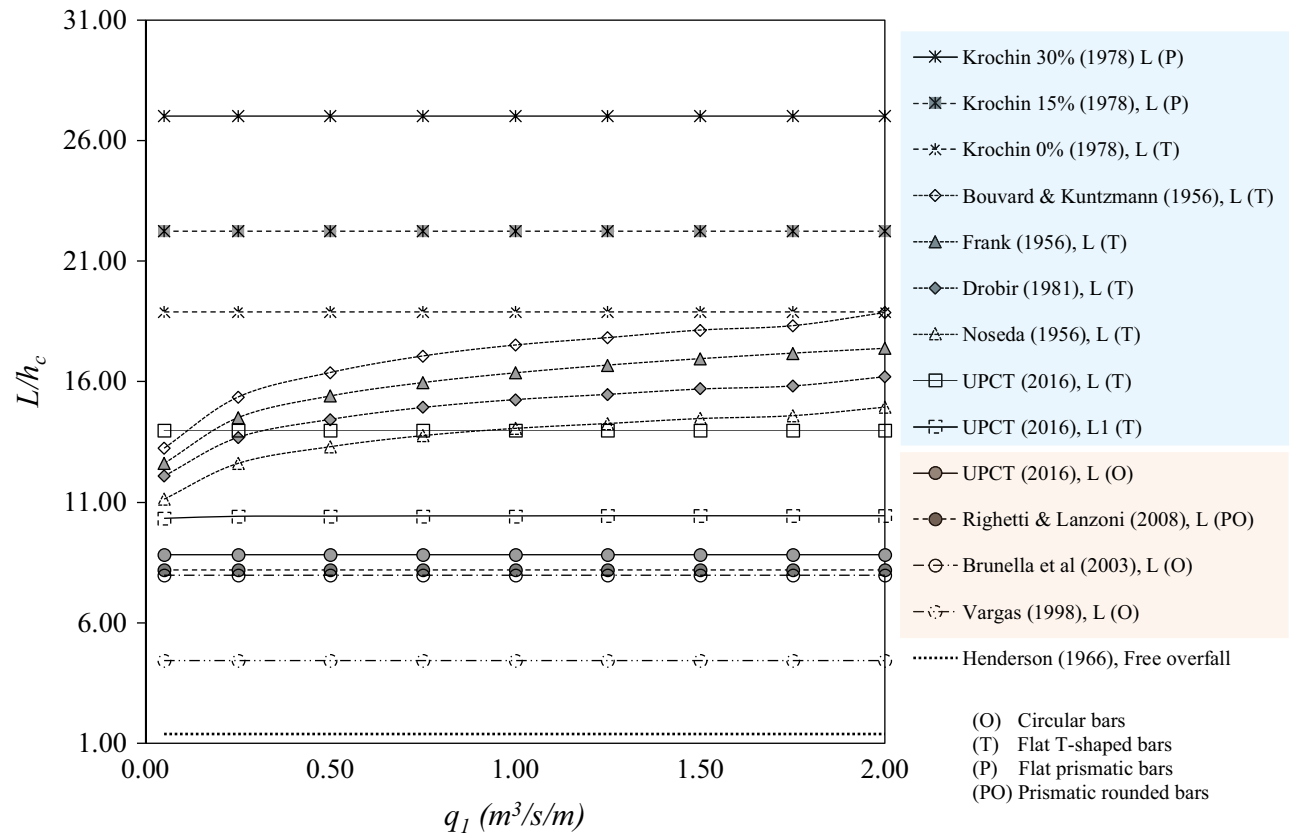

Figure 4: Dimensionless wetted rack length as a function of critical flow depth, $h_{c}$, approximation proposed in literature for racks with void ratio $m=0.12$. 
bars, dimensionless rack length as a function of critical flow varies from 10.40 to 18.90 when sediment occlusion is not considered. At the top of the Fig. 4 are the values of 22.20 and 27.00 , which correspond to dimensionless rack length as a function of critical flow with $15 \%$ and $30 \%$ of occlusion factor, respectively.

It is worth mentioning that bottom racks with $m=0.12$ could be used for small hydropower plants that need to capture small amounts of sediment to avoid damaging the turbine blades.

As shown in the previous figures, there are important differences in the dimensionless length of rack proposed by the researchers considered. This is due to variation of the parameters established for each experimental work. These parameters are: void ratio (normally, this value is set to $3 / 4\left(d_{90}\right)$ of riverbed sediment granulometry), bar shapes, rack slope or approximate conditions of the flow at the beginning of the rack.

Due to these differences, a summarizing figure is proposed where average results presented in Figs 2-Fig. 4 are shown. In order to generate Fig. 5, the representative curves were grouped, considering the following factors:

- Occlusion factor of the bottom rack. Formulae that considered the transport of sediments effect (Krochin 15\% and Krochin 30\% [1]) were separated from those made with clear water.

- Type of bar. The average value of dimensionless wetted length, $L_{\text {prom }}(T)$, was calculated using the formulae proposed by the different authors. In this way, Krochin 0\% [1], UPCT-T [2], Frank [6], Drobir [5], Bouvard \& Kuntzmann [7] and Noseda [8] formulae were considered for T-shaped bars. The expressions from UPCT-O [2], Brunella et al. [9] and Jimenez \& Vargas [10] were used for circular bars, $L_{\text {prom }}(O)$.

- Void ratio value was multiplied by each average dimensionless wetted length in function of the critical depth.

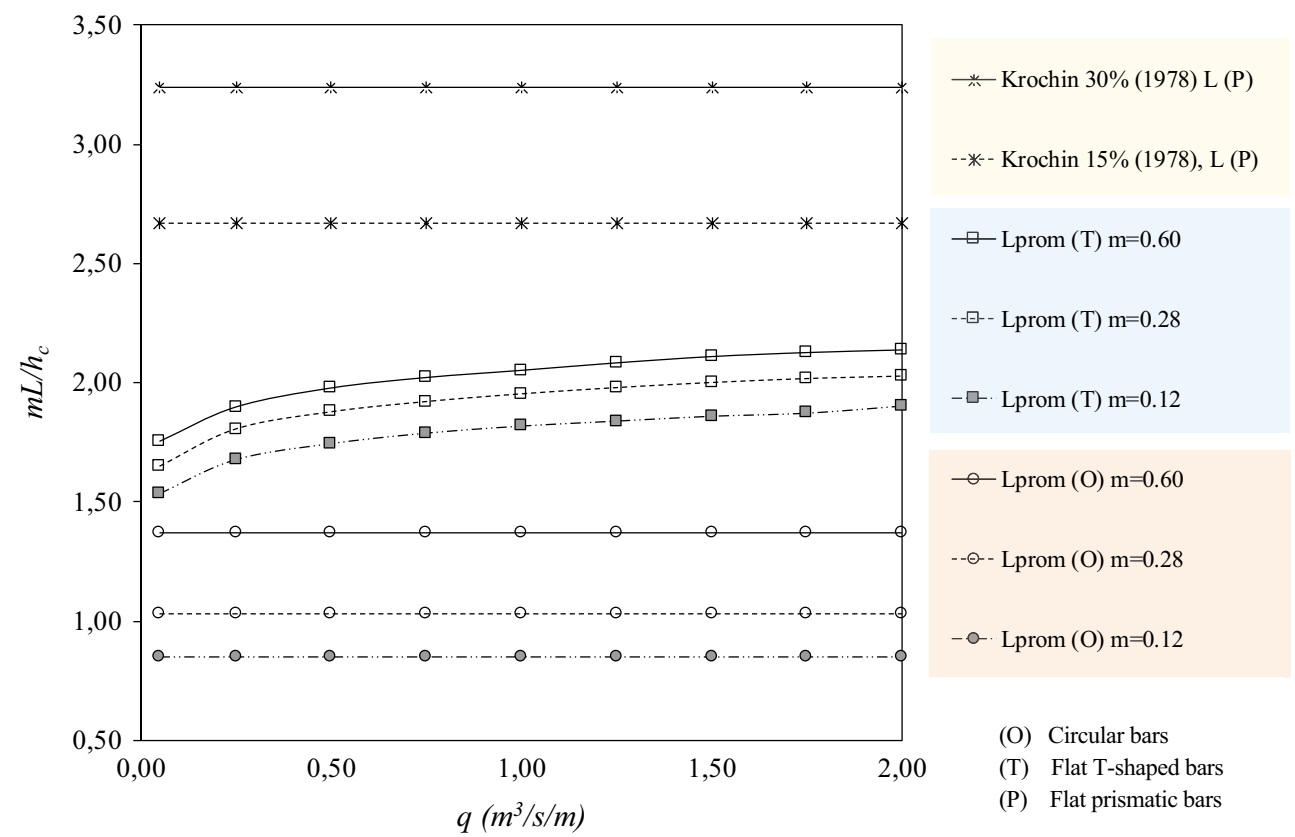

Figure 5: Dimensionless wetted rack length as a function of critical flow depth, $h_{c}$, multiplied by void ratio, $m$; considering bar shapes and occlusion coefficient. 
Table 1: Details of laboratory models used by Orth [11], Drobir [5], and Jiménez \& Vargas [10] in their research.

\begin{tabular}{llc}
\hline Scale type & Orth [11] $1: 5$ & Jiménez \& Vargas [10], Drobir [5] 1:10 \\
\hline Length scale & $L^{\prime} / L=1 / 5$ & $L^{\prime} / L=1 / 10$ \\
Velocity scale & $V^{\prime} / V=1 / 2.34$ & $V^{\prime} / V=1 / 3.16$ \\
Specific flow scale & $q^{\prime} / q=1.18$ & $q^{\prime} / q=31.62$ \\
\hline
\end{tabular}

Analysing the results presented in Fig. 5, Krochin's expressions for 15\% and 30\% occlusion factors in the bottom rack show no variation with the void ratio, so the figure includes only two lines without distinction of $m$. For the average dimensionless wetted lengths for T-shaped bars, the difference between the minimum and maximum void ratio is around $11 \%$ for a specific flow rate of $1 \mathrm{~m}^{3} / \mathrm{s} / \mathrm{m}$; while for circular bars, the difference between void ratios reaches $38 \%$ between $m=0.12$ and 0.60 for the dimensionless factor $m L / h$.

Some researches were performed in laboratory models, which have specific scale characteristics (Table 1), where Froude similitude hypothesis is assumed.

From this hypothesis, no differences should be found between the length calculated from model dimensions and that obtained using the same equations, for prototype dimensions, calculated according to Froude-similitude scale factors (Table 1). Prototype measurements [5] point to possible scale effects that should be further studied. With information available so far, it is concluded that equations proposed may be used at model or prototype scale without the appearance of any differences. To compare the model and prototype data, we used always the same void ratio for both cases.

\section{CONCLUSIONS}

Dimensionless wetted rack length for deriving a design flow is presented as a tool which can help in bottom intake systems design and complements previous works (Castillo \& Lima [4], Castillo et al. [12]).

The most important parameters that influence the value of wetted rack length are the void ratio and the bar shapes. Thus, in function of the kind of bar shapes (circular or flat) differences up to $50 \%$ are found for $m=0.60$; up to $89 \%$ for $m=0.28$ and $110 \%$ for $m=0.12$.

Dimensionless wetted rack length was calculated using prototype and model parameters for this work. Both cases present similar $L / h_{c}$ ratios, so the equations collected may be used for model or prototype data in order to obtain the same results while void ratio in both model and prototype is maintained. Anyway, prototype measurements presented by Drobir et al. [5] in Figure 2 point to possible scale effects that should be further studied.

Most formulations do not consider the occlusion of the rack as a result of sediment transport, except for the case of Krochin [1] that proposes an obstruction factor up to $30 \%$, which has been validated experimentally by Castillo et al. [3].

This work complements and updates what was made by Castillo \& Lima [4] in 2010, where a figure was presented that collected the existing wetted rack lengths proposed in the bibliography. In this case, dimensionless wetted rack lengths as function of critical flow are shown. Curves groupings by type of bar shapes are also presented; and the formulae and experimental conditions for which were obtained are summarized in the Appendix. In the same way, formulae are updated with new found expressions, such as Jimenez \& Vargas [9] and García [2]. 


\section{APPENDIX}

Table A1: Summary of wetted rack lengths to derive an approximation flow proposed in the literature (Castillo et al. [12]).

\begin{tabular}{llc}
\hline Reference & Experimental data & Wetted rack length $L(\mathrm{~m})$ \\
\hline Noseda [8] & $q_{1 \max }=100 \mathrm{l} / \mathrm{s} ;$ & $L=1.1848 \frac{E_{o}}{C_{q h} m} ;$ \\
& $B=0.50 \mathrm{~m} ;$ & $C_{q h}=\overline{C_{q h}(h) ;}$ \\
& $0.16<m<0.28 ;$ & $C_{q h}(h)=0.66 m^{-0.16}\left(\frac{h}{l}\right)^{-0.13}$
\end{tabular}

Bouvard \& Information taken from

Kuntzmann Noseda [8]

[7]

$$
\begin{gathered}
L=\left\{\frac{1}{2 m^{\prime}}\left[\left(j+\frac{1}{2 j^{2}}\right) \operatorname{arcsen} \sqrt{\frac{j}{j+\frac{1}{2 j^{2}}}}+3 \sqrt{\frac{1}{2 j}}\right]+\right. \\
\left.\left(\frac{0,303}{m^{\prime 2}}+\frac{2 j^{3}-3 j^{2}+1}{4 j^{2}}\right) \operatorname{tg} \theta\right\} h_{1} \cos \theta \\
j=\frac{h_{1}}{h_{c}}=1 ; \quad m^{\prime}=C_{q o} m ; \quad C_{q o}=0,82
\end{gathered}
$$

Frank [6] Information taken from

Noseda [8]

$$
\begin{aligned}
L & =2.561 \frac{q_{1}}{\lambda \sqrt{h_{o}}} ; \\
\lambda & =m C_{q h} \sqrt{2 g \cos \theta} ; \\
C_{q h} & =\overline{C_{q h}(h)_{\text {Noseda }}}
\end{aligned}
$$

Krochin [1] Information from Melik

Nubarov [13]

Prismatic flat bars

$$
\begin{aligned}
L & =\left[\frac{0.313 q_{1}}{\left(C_{q E} k_{1}\right)^{3 / 2}}\right]^{2 / 3} ; k_{1}=(1-f) m ; \\
C_{q E} & =C_{0}-0.325 \tan \theta ; \quad C_{0}=0.50
\end{aligned}
$$

Drobir [14] Information taken from Frank [6] and Bouvard \& Kuntzmann [7]

$$
L=\left[\frac{0.313 q_{1}}{\left(C_{q H} k_{1}\right)^{3 / 2}}\right]^{2 / 3} \quad ; \cos \theta x^{3}-3 x^{2}+1=0
$$

Drobir et al. $\quad q_{1 \max }=20 \mathrm{l} / \mathrm{s} ; B=0.50 \mathrm{~m}$; [5]

$m=0.60$

$$
\begin{gathered}
L_{1}=0.9088 q_{1}^{0.4993} ; \\
L_{2}=1.7205 q_{1}^{0.4296} ; \\
L_{\mathrm{TIWAG}}
\end{gathered}
$$$$
\text { Slope: 0-20\% }
$$ 
Table A1: (Continued)

\begin{tabular}{|c|c|c|}
\hline Reference & Experimental data & Wetted rack length $L(\mathrm{~m})$ \\
\hline $\begin{array}{l}\text { Brunella et al } \\
(2003)\end{array}$ & $\begin{array}{l}q_{1 \max }=100 \mathrm{l} / \mathrm{d} ; \\
B=50 \mathrm{~cm} \\
\text { Circular bars; } \\
\text { Two setups: } \\
m=0.352 \mathrm{~m}=0.664 \\
\text { Slope: } 0-51^{\circ}\end{array}$ & $\begin{array}{l}L=\frac{0.83 E_{0}}{C_{q 0} m} \\
C_{q 0}=0.87\end{array}$ \\
\hline \multirow[t]{3}{*}{$\begin{array}{l}\text { Righetti \& } \\
\text { Lanzoni [15] }\end{array}$} & $\begin{array}{l}q_{1 \max }=37.5 \mathrm{l} / \mathrm{s} ; \\
B=25 \mathrm{~cm} \\
\text { Prismatic rounded bars; } \\
m=0.20 ; b_{1}=0.50 \mathrm{~cm} ; \\
b_{w}=2.0 \mathrm{~cm}\end{array}$ & $\begin{array}{r}Q=C_{q 0} m B L \sqrt{2 g E_{0}}\left(\frac{a}{2} \frac{L}{E_{0}} F_{E 0}\right)+ \\
1\left\{\tanh \left[b_{o}\left(\sqrt{2}-F_{E 0}\right)\right]\right\}^{b_{a}}\end{array}$ \\
\hline & & $F_{E 0}=\frac{U_{0}}{\sqrt{g E_{0}}}$ \\
\hline & & $b_{a}=0.478$ \\
\hline
\end{tabular}

Jimenez \& $\quad q_{1 \max }=40 \mathrm{l} / \mathrm{s}$;

Vargas [10] $\quad B=55.2 \mathrm{~cm}$; circular bars

Slope: 0-20'

$L=k_{2} \sqrt{\frac{2 \cos \theta q_{1}^{2}}{m g h_{1}}} ; \quad k_{2}=1.10$

Two setups:

$m=0.33$ and $m=0.50$

García [2]

$q_{1 \max }=77.71 / \mathrm{s}$;

$0.16<m<0.28$;

$0.0057<b_{1}<0.0117$;

T-shaped bars;

Slope: 0-33\%
$L \quad L \approx 1.3 \frac{h_{\mathrm{c}}}{C_{q o} m}(1+0.3 \operatorname{tg} \theta) ; C_{q o}=a \cdot e^{-0.77 m}$
$a=1.43$
$a=0.90$

Circular bars

T-shaped bars

$$
\begin{gathered}
\mathrm{L} 1: \frac{\mathrm{dh}}{\mathrm{dx}}=\frac{2 m C_{q H} \sqrt{\left(E_{o}+x \operatorname{sen} \theta\right)\left(E_{o}+x \operatorname{sen} \theta-h \cos \theta\right)}+h \operatorname{sen} \theta}{3 h \cos \theta-2\left(E_{o}+x \operatorname{sen} \theta\right)} \\
C_{q E} \approx \frac{0.58 e^{-0.75\left(\frac{x}{h_{c}} m\right)}}{(1+0.90 \operatorname{tg} \theta)}
\end{gathered}
$$

Henderson

[16]

Free overfall: $L=1.40 h_{c}$

Note: For this table, it is considering that $h_{1}$ is the flow depth at the beginning of the rack; $h_{c}$ the critical depth; $h_{2}=0 ; E_{o}=\mathrm{E}_{\text {min }}$, the specific energy head at the beginning of the rack; $B$ the channel width; $q_{1}$ the specific approximation flow; $\theta$ the angle of rack with horizontal; $b_{1}$ the space between two bars; $b_{w}$ the bar width; $l$ the resultant of $\left(b_{1}+b_{\mathrm{w}}\right) ; F_{E o}$ the Froude Number at the beginning of the rack; $C_{q h}, C_{q E}$ and $C_{q o}$ the discharge coefficients in function of flow depth, energy head and static, respectively; $a, b$, $b_{a}$ and $k_{2}$ proper coefficients for the equations where they belong; and $f$ the obstruction factor $(\%)$. 


\section{ACKNOWLEDGEMENTS}

The authors are grateful for the financial support received from the Seneca Foundation of Murcia Region (Spain) through the project 'Optimización de los sistemas de captación de fondo para zonas semiáridas y caudales con alto contenido de sedimentos. Definición de los parámetros de diseño'. Reference: 19490/PI/14.

\section{REFERENCES}

[1] Krochin, S., Diseño Hidráulico. Segunda. Escuela Politécnica Nacional: Quito, 1978.

[2] García, J.T., Estudio experimental y numérico de los sistemas de captación de fondo. Ph.D. Thesis, Universidad Politécnica de Cartagena, 2016 (in Spanish).

[3] Castillo, L.G., García, J.T. \& Carrillo, J.M., Experimental and numerical study of bottom rack occlusion by flow with gravel-sized sediment. Application to ephemeral streams in semi-arid regions. Water, 8, p. 166, 2016. DOI: 10.3390/w8040166.

[4] Castillo, L.G. \& Lima, P., Análisis del Dimensionamiento de la Longitud de Reja en una Captación de Fondo. Proceedings of the XXIV Congreso Latinoamericano de $\mathrm{Hi}$ dráulica, Punta del Este, 2010.

[5] Drobir, H., Kienberger, V. \& Krouzecky, N., The wetted rack length of the Tyrolean weir. Proceedings of the IAHR-28th Congress, Graz, 1999.

[6] Frank, J., Fortschritte in der hydraulic des Sohlenrechens. Bauingenieur, 34, pp. 12-18, 1959 (in German).

[7] Bouvard, M. \& Kuntzmann, J., Étude théorique des grilles de prises d'eau du type (En Dessous). Houille Blanche, 5, pp. 569-574, 1956 (in French). DOI: 10.1051/ $\mathrm{lhb} / 1954049$.

[8] Noseda, G., Correnti permanenti con portata progressivamente decrescente, defluenti su griglie di fondo. L' Energia Elettrica, 33, pp. 41-51, 1956 (in Italian).

[9] Brunella, S., Hager, W.H. \& Minor, H.-E., Hydraulics of bottom rack intake. Journal of Hydraulic Engineering, 129, pp. 2-10, 2003. DOI: 10.1061/(ASCE)07339429(2003)129:1(2).

[10] Jiménez, Ó \& Vargas, O.A., Some experiences in the performance of bottom intakes. Proceedings of the International Symposium on Hydraulic Structures, IAHR: Guayana, 2006.

[11] Orth, J., Chardonnet, E. \& Meynardi, G., Étude de Grilles Pour Prises d'Eau du Type « En Dessous ». La Houille Blanche, 3, pp. 343-351, 1954 (in French). DOI: 10.1051/ $\mathrm{lhb} / 1954034$.

[12] Castillo, L.G., García, J.T. \& Carrillo, J.M., Influence of rack slope and approaching conditions in bottom intake systems. Water, 9, p. 65, 2017. DOI: 10.3390/W9010065.

[13] Melik-Nubarow, S.G., Type perfectionnè de prise d'eau à grille horizontale. Revue, N10-N11, 1939 (in French).

[14] Drobir, H., Entwurf vonWasserfassungen im Hochgebirge. Österreichische Wasserwirtsch, 11, pp. 243-253, 1981 (in German).

[15] Righetti, M. \& Lanzoni, S., Experimental study of the flow field over bottom intake racks. Journal of Hydraulic Engineering, 134, pp. 15-22, 2008. DOI: 10.1061/ (ASCE)0733-9429(2008)134:1(15).

[16] Henderson, F.M.N., Open Channel Flow, MacMillan: New York, NY, 1966. 